\title{
Effective Teaching Methods
}

\author{
Swinton Hudson
}

The movement from summative assessments, although still needed and used, has transitioned to a combination of summative and formative assessments. The focus in universities is no longer the successful completion of course material but the degree to which learning has occurred. Global needs, business input and demands, and generational cohorts have helped make student retention of information and practice significant. Based on empirical studies and demands, classroom assessment techniques (CATs) were developed. Thus, teaching techniques have transitioned from a memorization and regurgitation method to one of understanding concepts and theories and application. The need resulted in classroom assessment techniques, which focus on a formative assessment method. The concepts and techniques are used for all disciplines providing for a collaboration of efforts to ensure learning occurs. This paper will review the probability that CATs enhances learning and subsequently meet the business needs of critical thinking and associated skills.

\section{CLASSROOM ASSESSMENT TECHNIQUES: GOOD FOR BUSINESS - A SHORT CRITIQUE}

The intent of higher education is to prepare graduates with the necessary training to successfully integrate into society and provide benefits immediately to an organization. This is not only based on service to community but also the marketability and immediate impact on organizations where the graduate is currently employed or will be employed in the future. Business and global needs have had an impact on higher education by encouraging institutions to ensure students are marketable and provide immediate impact once hired. As businesses have become more "dynamic and complex," teaching too has taken a different approach (Cottell \& Harwood, 1998, p.37). The need for business-ready skills forced universities to change approaches to ensure graduates could meet these needs. Krell (2011) contended that education is flawed in meeting the needs of businesses, which is a critical skills gap within employees entering the workforce. Companies are in need of graduates who can work in teams, collaborate, problem solve, plan, and use critical thinking skills, resulting in higher education shifting current teaching models from memorization and regurgitation to application. Hence, classroom assessment techniques (CATs) have arisen.

\section{FORMATIVE AND SUMMATIVE ASSESSMENTS}

To fully understand CATs, knowledge of formative and summative assessments must be understood and the intent of the application of each. According to Angelo and Cross (1993), there is no effective teaching without learning. Summative assessments occur after the fact of teaching and not at a point during which learning occurs. This includes tests with or without associated feedback to measure results. With formative assessments, the process is intended to determine whether students are learning in time for the instructor to reinforce, explain, and expand the concepts and theories. In addition, the instructor can use the techniques to expand the knowledge and critical thinking of the student (Emanuel, Robinson, \& Korczak, 2013). CATs assessments help the instructor determine if learning has occurred. Then the instructor may modify and reinforce the concepts and provide examples to fortify the learning.

Thus, formative assessments are based on the theory of Bloom's Taxonomy (1956). Bloom's Taxonomy is centered on eliciting critical responses. The critical responses are levels of higher order questions or remembering, understanding, applying, analyzing, evaluating, and creating (Anderson \& Krathwohl, 2001). Another theory, which is ap- 
plied to formative assessments, is Kolb's Experiential Learning (1985). Experiential learning is conceived as a four-stage cycle:

(1) Immediate concrete experience serves as the basis for (2) observation and reflection. These observations are (3) assimilated into a "theory" from which new implications for action can be deduced. Finally, (4) these implications or hypotheses act as guides to create new experiences. Therefore, the learner relies on four different learning modes: Concrete Experience, Reflective Observation, Abstract Conceptualization, and Active Experimentation (Kolb, 1985). For experiential learning to be effective, an individual must be open to new experiences and participate without bias. He or she must reflect on those experiences from a range of points of view while also transforming those reflections into logical theories. The final step is to use these theories to make decisions and solve problems (Kolb, 1985). If this occurs, then learning has taken place through application of concepts and theory. Angelo and Cross (1993) stated:

See classroom assessment as likely to be beneficial to both teachers and students because it revolves around questions of immediate interest to them (rather than questions of outside researchers), uses accessible methods to collect data, and generates results that have clear implications for action and are thus likely to produce change. (p. 109)

\section{CLASSROOM ASSESSMENT TECHNIQUES}

Classroom assessment techniques are teacherdirected, content-specific, learner-centered formative assessments that are ongoing (Angelo \& Cross, 1993; Johnson, 2008). The results include more highly developed critical thinking and problem solving skills (Embretson, 2010). Highly contextualized tasks that measure critical thinking can increase the substance and validity of this process. The use of reflective questions and expansion of thinking using deductive and inductive reason results in critical thinking (Johnson, 2008). The inference can then be made that CATs are part of the critical thinking construct.

Critical thinking is a major goal of education with an inclusion of theory and practical application (Johnson, 2008). This is the incorporation of both inductive and deductive reasoning. This is also a desired skill of businesses (manufacturing, research and development, service industry, health care, or academics). Critical thinking, inductive and deductive reasoning, develops problem-solving skills, which are a skill sought after by businesses. In the Taxonomy of Educational Objectives, Bloom (1956) proposed six levels of thought. Each level in the hierarchy builds upon the previous level; cognitive skills learned at one level play a part in thinking at the next successive level. The six levels are knowledge, comprehension, application, analysis, synthesis, and evaluation.

Thus, for student learning to occur, the teacher uses assessment techniques to move the student to higher levels of analysis, synthesis, and evaluation. Johnson (2008) contended that critical thinking covers a variety of outcomes such as elements of reasoning, intellectual abilities, modes of reasoning, traits of mind, intellectual standards, reason in actions and beliefs, questioning assumptions, ability to generalize and invent new possibilities, and intellectual independence. This is part of critical thinking and moves the student away from just memorization and regurgitation to more of an application of theory and concepts. Since CATs are divided into 10 sections or levels of assessment and techniques to ensure learning has occurred, the outcomes likely result in application of best practices, concepts, and theory.

Part of business' needs with innovation and creativity are developed through declarative learning, focus on analysis, stimulating students to create, problem solving, and knowing when and where to apply what is known and what one can do. CATs help students focus on recognizing types of problems, determining principles and techniques to solve these problems, perceiving similarities of problem features, and gaining the ability to reflect and then alter solution strategies, which manifests into innovation and creativity. Again, 21st century businesses are in need of these skills for innovation and creativity to remain competitive.

Angelo and Cross (1993) proposed a process for effective CATs consisting of planning, implementing and responding. The planning phase is designed to pick a learning objective, to identify an assessment to provide the type of feedback desired, and to explain the purpose of the assignment to students. In the implementation phase, the instructor collects the feedback and then analyzes the feedback. The final phase is responding, which consists of interpreting the results and formulating 
a response to affect learning. The student communicates the results and reflects on the experience. This formative assessment occurs during the teaching process and ensures expansion of knowledge, as well as critical thinking and application of concepts and theory. This goal of CATs is to improve teaching and learning.

Angelo and Cross (1993) have developed 50 different CATs for instructors to use which assess at different levels and needs based on the objectives and needs of the instructor and students. The categories are assessing prior knowledge and experience, which checks declarative knowledge and associates knowledge with experience and concepts related to course objectives. The next category of techniques is based on analysis and critical thinking. As the progression occurs, students assess creative thinking and synthesize theory and concepts, as well as assess skill in problem solving by utilizing the objectives taught. The last category assesses application and performance by ability to apply the concepts taught. Although there are other categories, which show reaction and provide additional feedback on feelings, self-awareness, study skills, behaviors, and strategies, the first five are a good foundation for assessing learning. The techniques are adjustable guidelines or frameworks to support the learning model with integrated tools (Wesiak, Al-Smadi, Höfler, \& Gütl, 2013).

In Steadman's (1998) research, she contended that the purpose of CATs is to "to obtain feedback on teaching and classroom activities, to improve teaching, to monitor student learning, to improve communication and collaboration with students, and to improve student learning" (p. 34). CATs' purpose, as previously stated, is to affect learning. This means that learning does not occur through memorization of concepts and facts that are housed in short-term memory. For actual learning to occur, the information must be transferred to long-term memory. Thus, assessment and reinforcement helps this occur. Another point for learning to occur is to ensure one can apply the knowledge gained. Today's businesses are in need of graduates who can apply theory and concepts. Following Kolb's Experiential Learning Model (1985), learning will occur when there is reflection, observation, immediate application of concrete experience, and assimilation of theory into practical application.

\section{CONCLUSION}

The need of businesses is for graduates of higher learning institutions to arrive in the global business environment with the ability to think critically, work in teams, and use good problem solving techniques. Faculty should integrate new techniques, offer new forms of feedback, and make efforts to improve the quality of teaching and learning. The continued use, support, and promotion of classroom assessment techniques has the potential to move educational institutions forward on their journey of continuous quality improvement. Feedback is necessary for student learning, including written, verbal, individual, and group, which patterns classroom assessment techniques (Randall \& Zundel, 2012). According to Cottell and Hardwood (1998):

CATs offer a valuable supplement to these traditional approaches because they are formative and based on an ongoing student-professor feedback loop. Thus, professors can improve student learning by using the feedback from CATs to exercise greater discretion over when and how to make midcourse adjustments. (p.40)

Using these techniques, faculty are able to move students to a higher level of learning; this moves beyond teaching, but more to motivation, mentoring, and modeling by application of concepts and theories and not just memorization and regurgitation. This can be accomplished through CATs, which help meet the needed skills for businesses and successfully integrate students into society and provide benefits immediately to businesses. This manuscript is not an empirical study of results but is a critique of theories, which are supported by universities. Without a long-term measurement of results, the actual gains can only be achieved by following a control group into the business world who have been exposed to CATs during college and determining the results by surveying businesses. 


\section{REFERENCES}

Anderson, L. W., \& Krathwohl, D. R. (Eds.). (2001). A taxonomy for learning, teaching, and assessing: A revision of Bloom's taxonomy of educational objectives. New York: Longman.

Angelo, T. A., \& Cross, K. P. (1993). Classroom assessment techniques: A handbook of classroom assessment techniques for college teachers. San Francisco: Jossey-Bass.

Bloom B. S. (1956). Taxonomy of educational objectives, handbook I: The cognitive domain. New York: David McKay Co., Inc.

Cottell, P. \& Harwood, E. (1998). Do classroom assessment techniques (CATs) improve student learning? New Directions for Teaching and Learning, 1998(75), 37-46.

Emanuel, D. C., Robinson, C. G., \& Korczak, P. (June, 2013). Development of a formative and summative assessment system for AuD Education. American Journal of Audiology, 22, 14-25.

Embretson, S. (2010). Cognitively based assessment and the integration of summative and formative assessments. Measurement, 8, 180-184.

Johnson, D. C. (2008). Thinking critically about assessing online learning. The International Journal of Learning, 14(12), 125130.

Krell, E. (2011). The global talent mismatch. HR Magazine, 56(6), 68-73.

Krell, E. (2012). Retool your public-private partnership. HR Magazine, 57(5), 41-46.

Kolb, D. (1985). Learning style inventory. Boston, MA: McBer and Company.

Randall, L. \& Zundel, P. (2012). Students' perceptions of the effectiveness of assessment feedback as a learning tool in an introductory problem-solving course. The Canadian Journal for the Scholarship of Teaching and Learning, 3(1). http:/l dx.doi.org/10.5206/cjsotl-rcacea.2012.1.3

Steadman, M. (1998). Using classroom assessment to change both teaching and learning. New Directions for Teaching and Learning, 1998(75), 23-35.

Wesiak, G., Al-Smadi, M., Höfler, M., \& Gütl, C. (2013). Assessment for complex learning Resources: Development and validation of an integrated model. iJET, 8(1), 52-61.

\section{Author Biography}

Swinton Hudson was born in South Carolina and currently resides in Columbia, South Carolina. After a career with the Federal Government and Army National Guard (Reserves), he chose to retire and pursue other interests. His assignments with the Federal Government included Information Technology Supervisor, Operations manager, Training Manager and Human Resources and the Director of Human Resources Governor's Office of Executive Policy and Programs.

Swinton earned a Masters of Arts degree with a specialization in Business Management from Liberty University, a Bachelor of Science degree in Business Management from Liberty University and an Associate of Business degree from Midlands Technical College. He received specialized training and certification at the Defense Equal Opportunity Management Institute and Dale Carnegie Corporation, as well as the Equal Employment Opportunity Commission (EEOC).

He has been an adjunct instructor with Grand Canyon University since 2010 in the Colangelo College of Business. 